\title{
Aftercare: who attends section 117 meetings?
}

\author{
Rosemary Lethem
}

The purpose of aftercare is to enable patients to return to their home or accommodation other than a hospital or nursing home, and to minimse the need for future in-patient care. Under section 117 of the Mental Health Act 1983. local health and social services authorities have a legal duty to provide aftercare for certain categorles of patients when they leave hospital (Department of Health and Welsh Office, 1993).

The responsible medical officer (RMO) must ensure that a discussion takes place to establish a care plan (Kingdon, 1994). According to the Code of Practice. Mental Health Act 1983 (Department of Health and Welsh Office 1993), those who should be involved are the patient's RMO; a nurse involved in caring for the patient in hospital; a social worker (SW) specialising in mental health work; the general practitioner (GP); a community psychiatric nurse (CPN); representatives of relevant voluntary organisations where appropriate; the patient and/or relattves or other nominated representattve. The plan should be recorded in writing.

A review of section 117 meeting records was undertaken to survey the involvement of mental health care professionals in planning aftercare for discharged psychiatric inpatients in one inner London psychiatric unit.

Records of section 117 meetings are kept centrally by the hospital's Mental Health Act administrator. These should document the date of the meeting, those attending, and those invited but unable to attend. The responsible medical officer, general practitioner and social worker should be indtvidually identified. Soctal workers may be hospital or community based. All records identified as applying to meetings held within

Table 1. Attendance at section 117 meetings in 1991 and 1994. (categorles not necessarlly exclustive)

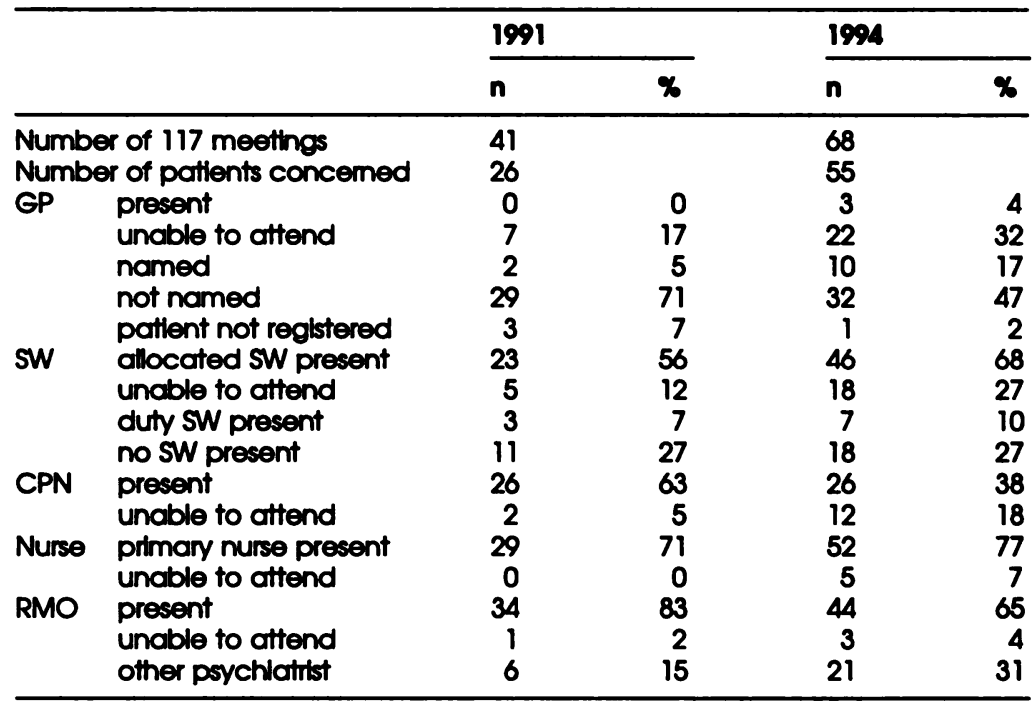


a particular period of interest were studied and this information recorded. The periods selected were 1994 to date, and 1991 for comparison.

The attendance of various mental health professional care workers is summarised in Table 1.

More meetings were held in 1994 than in 1991 and they were better documented, as is shown by the greater proportion of GPs identified, although in nearty half the records in 1994 the GP's name still did not appear. Attendance of hospital based doctors and nurses was higher than community based workers. This is particularty noticeable in the case of CPNs, where the attendance rate dropped from 63\% in 1991 to $38 \%$ in 1994. A doctor (a senitor registrar or consultant) was present at all meetings. Many more workers were recorded as invited but unable to attend in 1994 than in 1991. Very few GPs attended the meetings: none in 1991 and three in 1994; all the cases concerned were under the care of the same RMO, a newly appointed consultant. The soclal worker allocated to the case was present at fust over half the meetings in 1991 and two-thirds in 1994.

These findings demonstrate that GPs rarely attend section 117 meetings, and were not even named on the record form in nearly half of recent meetings. It can be argued that the presence of the GP, although destrable, is not realistic or necessary, in that his or her main function will probably be to supervise the patient's medication and this can be communicated adequately at discharge. As these results show, however, it is possible successfully to encourage at least some GPs to attend.

The need for involvement of CPNs and social workers is much less contentious, yet both groups were poorly represented, which gives cause for concern. Absence of a soctal worker seriously compromises what can be achieved in the meeting. In many instances hospitalbased social workers attended, although it is preferable that a community-based social worker local to the discharged patient is involved. The most recent sequence of meetings examined, in Aprll to July 1994, showed the most worrying trend of all, which was that in $39 \%$ of meetings the allocated soctal worker was unable to attend. The reason for this is not known, although one may speculate about pressure of work in the light of London's perpetual acute bed crisis and other signs of overload in the psychiatric care system (Cold, 1994). Short notice of the meeting date was suggested as a contributory cause.

This was a descripttve study based on recorded data. It could be argued that deficiencies in the records do not necessarily reflect shortcomings in the procedures but this is unilkely in view of the fact that there is a statutory requirement to keep written records and the information sought is very basic. Simply to achieve a gathering of relevant health care professionals in order to plan rationally for the patient's discharge was not possible in a very high proportion of cases during the periods studied.

\section{Reforences}

CoID. J. W. (1994) The Christopher Clunis enquiry. Psychiatric Bulletton, 18, 449-452.

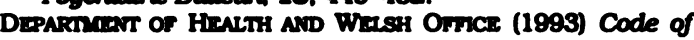
Practice, Mental Health Act 1983.

Kmodow. D. (1994) Care programme approach. Recent government policy and legialation. Paychiatic Bullettr. 18. 68-70.

Rosemary Lethem, Sentor Registrar, Mental Health Care of Older People, A8, Archway Wing, 4th Floor, Whittington Hospttal, Highgate HII, London N19 5NF 